\title{
Tabla de materias plásticas utilizables en la construcción
}

Cahiers du Centre Scientifique et Technique du Batiment, n' $19 .-1034$, moy०, 1971

Esta tabla tiene una entrada para la materia y otra para sus "empleos" en el ámbito de la construcción. Si se compara con las ediciones sucesivas se podrá apreciar la progresión en sus aplicaciones.

El círculo en blanco significa que el "empleo de un material" se encuentra en estado de investigación. Más adelante podrá señalarse con medio círculo negro, lo cual quiere decir que ya existen realizaciones en plan experimental. El círculo negro corresponde a un material plástico que ya se utiliza corrientemente en la construcción. Esto no significa que el empleo de tal o cual material plástico para tal uso sea definitivo, sino que implica un estado de hecho.

Desde 1964 vienen empleándose nuevas composiciones de resinas, como por ejemplo las PVC-ABS y las PVC con exceso de cloro, entre las termoplásticas.

En el campo de los termorresistentes han aparecido diversos poliésteres que tienen buena resistencia a la hidrólisis o al fuego y que son superiores a los poliésteres maleicos corrientes. Sin embargo, estos últimos continúan siendo los más utilizados en las fabricaciones corrientes de estratificados vidrio-resina.

En lo que se refiere a los elastómeros, se viene observando un claro aumento en sus empleos, particularmente como material para juntas.

Por el contrario, se nota una cierta desaparición, por ejemplo, de las resinas de urea-formol, utilizadas en espumas para aislamiento térmico.

Las poliamidas no han encontrado todavía su sitio, pero figurarán, sin lugar a dudas, en las ulteriores revisiones de esta Tabla.

En lo que se refiere a los empleos, la clasificación adoptada es: obra principal, elementos exteriores, elementos interiores, instalaciones, semi-productos. Esto concuerda con diferencias reales de fabricación y de exigencias, como por ejemplo la carpintería exterior (ventanas en fachadas) y carpintería para interiores (diferentes clases de puertas, rígidas o flexibles). 
Algunas de estas fabricaciones se han desarrollado gracias a las propiedades intrínsecas de los nuevos materiales utilizados. Como nuevos empleos experimentales cabe señalar: los hormigones ligeros con árido alveolar y aglomerante de resinas, los encofrados hechos con resinas termoplásticas. Resulta bastante fácil señalar los empleos reales, pero es muy difícil conocer las toneladas de materias utilizadas. El consumo en la construcción, que representaba, en 1960, el $15 \%$ aproximadamente del consumo total de plásticos en Francia, no ha seguido en efecto el crecimiento de producción de las resinas, pues éstas parecen situarse actualmente entre el 12 y el $14 \%$.

Con vistas a posteriores revisiones, todas las observaciones pueden ser dirigidas al Servicio de Documentación de Plásticos, de la Biblioteca del CSTB.

Por otra parte, sobre la base de la documentación y de las reseñas bibliográficas se han reunido bibliografías, de las cuales se facilita seguidamente una lista.

\section{Lista de las bibliografías que se refieren a las materias prácticas}

1. Espumas.

2. Paneles de fachada, muros-cortina, y paneles-sandwich.

3. Invernaderos.

4. Los cauchos.

5. Materias plásticasi y prefabricación.

6. Tuberías.

7. Estratificados.

8. Cerramientos y techos en materias plásticas.

9. Estructuras hinchables.

10. Piscinas.

11. Resistencia al fuego de las materias plásticas.

12. Comportamiento mecánico y reológico.

13. Materias pásticas y hormigón.

14. Materias plásticas en la carpintería.

15. Materias plásticas sanitarias.

16. Resinas polivinílicas.

17. Resinas acrilicas.

18. Los materiales plásticos en los países cálidos.

19. Materiales plásticos y covertura.

20. Generalidades sobre el empleo de los plásticos en la edificación.

21. Las resinas fenólicas.

22. Producción y consumo.

23. Envejecimiento por la intemperie y la luz de los materiales plásticos.

24. Las poliamidas.

25. Películas y hojas plásticas.

26. Casas en plástico.

27. Moldes para hormigón. Revestimiento de los hormigones.

28. Los poliésteres.

29. Revestimientos murales.

30. Materiales plásticos. Generalidades.

31. Resinas epoxílicas. Reparación de fisuras.

32. Siliconas. Hidrófugos (ver también MP 29).

33. Pegado del hormigón.

34. Construcciones desmontables en materiales plásticos.

35. Propiedades mecánicas de los materiales plásticos.

36. Los materiales plásticos y la iluminación. 


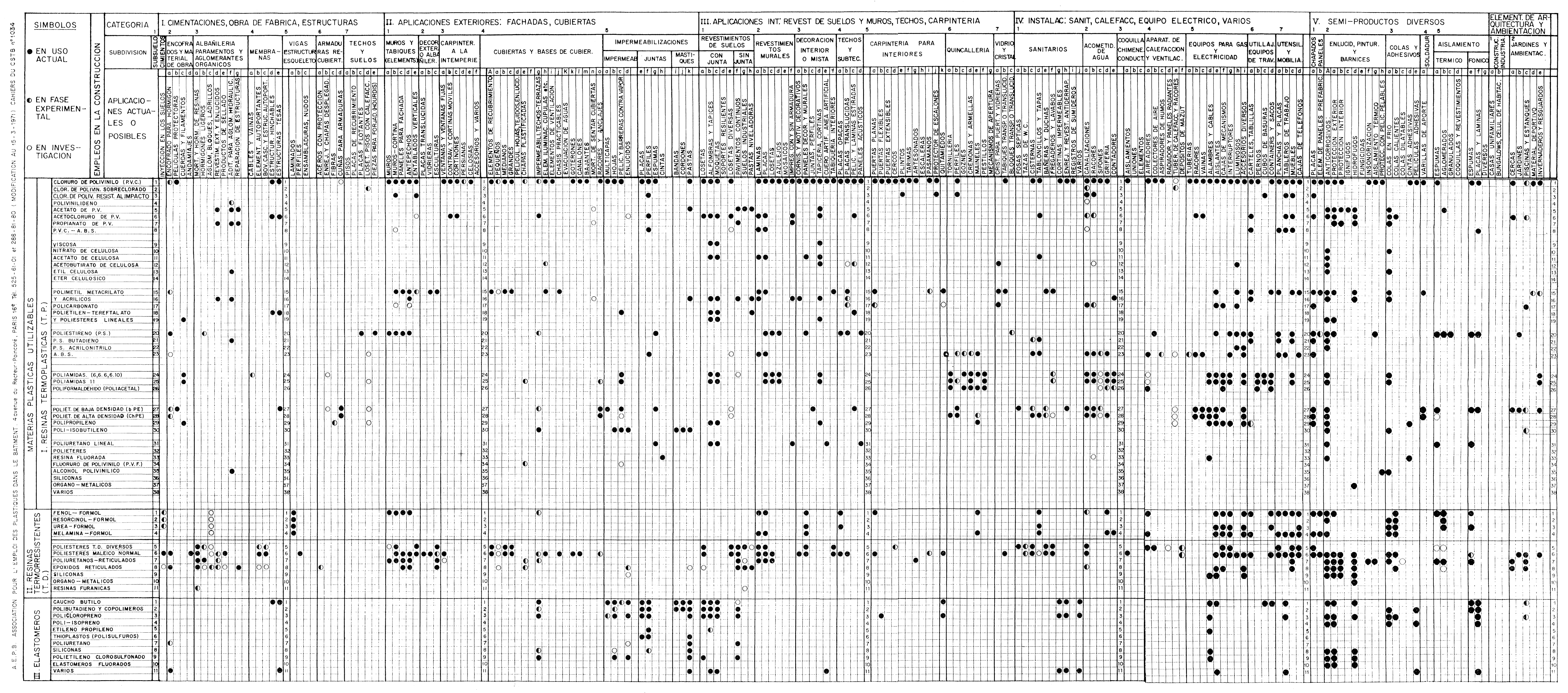

